\title{
Efficient and selective method to separate triterpene acids by direct treatment of apple peels with alkaline ethanol
}

\author{
João Batista de Freitas Tostes, Marcos Jun Nakamura, Caroliny Gomes \\ Franca de Saboya, José Luiz Mazzei \& Antonio Carlos Siani
}

To cite this article: João Batista de Freitas Tostes, Marcos Jun Nakamura, Caroliny Gomes Franca de Saboya, José Luiz Mazzei \& Antonio Carlos Siani (2016): Efficient and selective method to separate triterpene acids by direct treatment of apple peels with alkaline ethanol, Separation Science and Technology, DOI: 10.1080/01496395.2016.1200088

To link to this article: http://dx.doi.org/10.1080/01496395.2016.1200088

Accepted author version posted online: 17 Jun 2016.

Published online: 17 Jun 2016.

Submit your article to this journal $\asymp$

山 Article views: 4

Q View related articles $\longleftarrow$

View Crossmark data $\nearrow$ 
TITLE

\section{Efficient and selective method to separate triterpene acids by direct treatment of apple peels with alkaline ethanol}

\section{AUTHORS AND AFFILIATION}

João Batista de Freitas Tostes, Marcos Jun Nakamura, Caroliny Gomes Franca de Saboya, José Luiz Mazzei* \& Antonio Carlos Siani

Fundação Oswaldo Cruz, Instituto de Tecnologia em Fármacos. Rua Sizenando Nabuco 100, Manguinhos, Rio de Janeiro, 21041-250, Brazil.

*Corresponding author: José Luiz Mazzei. Tel: +55-21-3977-2512, email: mazzei@pq.cnpq.br.

\section{ABSTRACT}

Triterpene acid extraction from dried apple peels of Fuji and Gala varieties in $2 \% \mathrm{NaOH} / \mathrm{ethanol}$ at room temperature, followed by filtration and acidification $(\mathrm{pH} 3)$, was investigated, comparing to a classical exhaustive extraction (Soxhlet, 2h, with ethanol and methanol, $>97 \%$ recovery). Alkali-ethanol process yielded $4.35-6.86 \%$ (w/w) of whitish extracts, up to 15-times less than Soxhlet but with same recovery $(\mathrm{P}>0.05)$ of ursolic and oleanolic acids. Alkaline extraction of previously defatted peels led to same recovery $(\mathrm{P}>$ 
$0.05)$, but the yield increased slightly $(\mathrm{P}<0.01)$. The cost-effective and environmentalfriendly procedure prepares triterpene-rich extracts from apple peels at high recovery, directly eliminating the cutin and avoiding prior treatments with hazardous organic solvents.

\section{Keywords}

apple peels; triterpenes; ursolic acid; cutin depolymerization; extraction

\section{INTRODUCTION}

Ursolic acid is a ubiquitous ursane-type triterpene that is present in diverse plant organs, especially in the epidermal leaf and fruit cuticles [1]. Its chemical structure constitutes a $\Delta^{12-}$ ${ }^{13}$-pentacyclic hydrocarbon moiety that bears a secondary hydroxyl and an acid carboxyl group in the C-3 and C-17 positions, respectively (Fig. 1). It possesses a wide spectrum of pharmacological activities [2] and a high potential for phytopharmaceutical development $[3,4]$. Thus, the search for exploitable sources of ursolic acid has increased [5]. In this context, apple peels represent a promising source for large-scale exploitation of this compound [5]. Moreover, the apple pomace that is generated during the industrial processing of apple juice, and other derivatives [6,7], represents a suitable by-product to meet such a goal.

Studies on the nutritional value of apples in general, or specifically their peels or pulp, have typically converged to polyphenol-rich extracts and isolated substances that possess valuable antioxidant and anti-proliferative activity on tumoral cells $[8,9]$. However, since the identification of ursolic acid in apple peels [10], a series of studies has shown that such a component reaches up to $32 \%$ of the total lipophilic compounds in this plant matrix $[11,12]$. 
Ursolic acid is always accompanied by a minor amount (around one fifth) of the isomeric oleanolic acid in apple peels [11,13]. Furthermore, besides a plethora of other long-chain lipophilic compounds [14] and minor triterpene derivatives [15], the apple peel is also known to be rich in cutine. This is constituted by a complex mixture of phenolic esters that are derived of hydroxy and epoxy fatty acids. This natural biopolymer provides a net structure embedding both lipophilic and hydrophilic molecules to furnish the fruit coating $[16]$.

\section{BACKGROUND}

The earliest studies on the lipophilic composition of apple peels $[10,17,18]$ have focused on the elucidation of long-chain alkanes and alcohols and the characterization of ursolic acid between 1923 and 1931. The extraction of dried milled peels with petroleum ether followed by ethyl ether was established as a general method. The former solvent concentrates the linear alkanes, fatty acids and alcohols and the latter one extracts triterpene acids and other compounds [19,20]. Particularly, to isolate and identify triterpene acids [21], such a procedure has been preferred during following decades, even at the cost of eventually not exhausting the targeted compounds from the matrix.

The effective extraction of the plant metabolites strongly depends on their solubility and capacity to be transported through specific chemical environments (mass transfer). Triterpene acids are unlikely to meet both of these requirements efficiently, since they are poorly soluble in aqueous medium and many common organic solvents [22,23], and their removal from the plant tissues are subject to undesirable saturation by other co-extracted metabolites $[3,24]$. Thus, development of techniques that combine the proper solvent with a set of cost-effective operational conditions is required to scale-up effective processes of 
triterpene acid extractions from apple peels, aiming either to standardize extracts or to purify these compounds [25]. Moreover, an adequate extractive pre-treatment procedure to analytically detect and quantify these types of compounds must be available [26]. Hence, the literature on analysis of triterpene acid-based matrices also deserves particular attention because variations of solvent compositions strongly influence the material dissolution and elution steps.

\section{Solvent Extraction}

It has been reported that pure ursolic acid may dissolve in less conventional solvents, such as dioxane and tetramethyl urea [22], and in hot glacial acetic acid and 2\% $\mathrm{NaOH}$ in ethanol [23]. Nevertheless, the solubility parameters may not be directly applicable when dealing with the extraction of complex plant matrices that contain a series of other types of compounds that may either help or hamper the extraction process. Thus, the solvent should also be suitable to penetrate the tissues and reach the proper cells to solvate the triterpene acid. Although ethyl ether is slightly more effective than alcohols at solubilizing pure ursolic and oleanolic acids [23], these latter solvents produce a larger amount of extract due to their higher capacity to percolate the peel matrix $[27,28]$.

The use of medium- and high-polar solvents for extracting apple peel usually brings variable amounts of cutin into the extracts. The presence of such a compound after removing the solvent produces highly viscous extracts that must be properly partitioned to release the triterpene acids $[19,29]$.

The use of hydrated alcohols to extract apple is a typical procedure to approach their hydrophilic constitution, as briefly reviewed recently [30]. However, the use of $50-80 \%$ hydrated acetone has gradually become the preferred method to achieve this goal $[6,8,9,31]$. 
In these cases, the primary focus on the nutraceutical potential of the raw material or the apple in natura has led to the neglect of the extract yields, and data on the yields have been scarcely reported. The static maceration of Fuji apple peels in a 7:3 ethanol:water at room temperature yielded approximately 50\% (w/w) of extract [24], whilst the use of methanol, after sequential maceration with $n$-hexane and chloroform, yielded $66 \%(\mathrm{w} / \mathrm{w})$ of extract [27]. A series of extraction methods have been used to recover triterpene acids from plant matrices, as recently reviewed elsewhere [32]. Among these, the ultrasound-assisted processes have become the preferred method to maximize the yields of the targeted compounds [25,32] and to achieve satisfactory selectivity by choosing the appropriate solvent. Assays that involve several solvents and heat reflux extraction have demonstrated that $80 \%$ ethanol reached a maximum recovery of ursolic acid from dried whole Hedyotis diffusa plants under specific experimental conditions [25]. This result was consistent with that found during the investigations on the solubility parameters of the pure compound [22].

Methanol has also been the choice, either to separate the cutin of the apple aiming to the determination of its chemical composition [33] or to remove it from the extracts to isolate epoxy- or hydroxy-fatty acids $[19,29]$. The methanol extracts have usually been refluxed in alkaline $(\mathrm{NaOH}$ or $\mathrm{KOH} 0.5-15 \%)$ aqueous or alcoholic solutions $[34,35]$.

\section{Alkaline Extraction}

Depending on the chemical stability of the targeted compounds, a hydrolytic procedure in alkaline medium may be applied to the extracts to degrade the cutin. This procedure is known as cutin depolymerization [16], and it eventually could be used to remove the resulting soluble acids and phenols. Hence, refluxing intractable cutin-based cuticle extracts in aqueous and hydro-alcoholic alkaline $(\mathrm{NaOH}$ or $\mathrm{KOH})$ solutions has been employed to 
characterize triterpene and fatty acids $[10,32,36]$ as well as to produce suitable samples for fatty acid identification and quantification [37,38]. Additionally, the hydrolysis of raw plant tissues in alkaline alcohol has been reported to investigate the hydroxy- and epoxy-fatty acid constituents of cutin [39]. In addition, many common materials used in industry are chemically compatible with the diluted alkaline solutions at mild temperatures, as example of copper, stainless steel types 304 and 316 and the majority of the polymers [40].

\section{Previous Defatting}

Previous defatting of apple peels with $n$-hexane led to cleaner and wax-free ethanol extracts for the HPLC analysis with minimal loss of the targeted compound [41]. The same occurred in an experiment involving the leaves of six Myrtaceae species, where the treatment of dry leaves with n-hexane during 4 days at room temperature did not cause losses greater than $1.3 \%$ in the contents of triterpene acids. Additionally, the subsequent alkaline ethanol treatment of this defatted material produced more selective extracts, enhancing the levels of acids up to $4-13 \%[42,43]$. A 1-h heat-reflux extraction of some medicinal Rubiaceae species (whole plant) in $n$-hexane did not produce a detectable amount of the triterpene acids [25].

This study reports a cost-effective method to extract triterpene acids from apple peels (Malus domestica Borkh.) by directly applying the cutin alkaline depolymerization procedure to the peel matrix at room temperature, followed by the acid-base partitioning. This procedure was inspired by earlier procedures to depolymerize the cutin from fruit and leaf cuticles that is carried onto the extracts, thus favoring the release of the plant metabolites. The peel extracts that result from distinct batches of Malus domestica Borkh. cv. Fuji and Gala were analyzed using High Performance Liquid Chromatography (HPLC) 
to determine the ursolic and oleanolic acid contents. The amounts of the recovered acids were compared to those produced by exhaustive Soxhlet extraction using absolute alcohols and to a previously $n$-hexane defatted material.

\section{MATERIALS AND METHODS}

\section{Chemicals and Reagents}

The ursolic (purity $\geq 90 \%$, art. U6753) and oleanolic (purity $\geq 97 \%$, art. O5504) acid standards were purchased from Sigma-Aldrich Co. (St Louis, MO, USA). Ethanol (99.9\%), $n$-hexane $(95 \%)$ and $85 \%$ phosphoric acid were purchased from Merck Co. (Darmstadt, Germany). Sodium hydroxide and hydrochloric acid were supplied by Vetec (Xerém, BR). The HPLC/UV grade acetonitrile and methanol were purchased from Tedia (Fairfield, $\mathrm{OH}$, USA). Ultrapurified water (resistivity $18.1 \mathrm{M} \Omega-\mathrm{cm}$ ) from a NanoPure Diamond system (Barnstead/Thermolyne, Dubuque, IA, USA) was used throughout the chromatographic analysis. The other solvents and reagents were analytical-grade.

\section{Fruit Material}

Batches of medium-to-large sized commercial apple fruits were obtained in grocery retail markets during different periods between 2010 and 2013 in the city of Campinas, SP, Brazil. They were named as AF1 (9.00 Kg, May 2011), AF2 (5.06 Kg, May 2010) and AF3 (17.2 Kg, May 2013) for cv. Fuji; and AG1 (10.1 Kg, August 2011) and AG2 (6.11 Kg, June 2009) for cv. Gala. The fruits were peeled using a culinary manual peeler to obtain thin slices of fresh material that were oven-dried intermittently 3 times at $100{ }^{\circ} \mathrm{C}$ for $4 \mathrm{~h}$, 
followed 7 consecutive days at $45{ }^{\circ} \mathrm{C}$ under a constant flow of air affording a constant moisture content $(6.0 \pm 0.5 \% \mathrm{w} / \mathrm{w}$ for both batches $)$, which was determined using a moisture analyzer (series ID, version 1.8, Marte, Brazil). The dried pieces of peel were milled using a blender and then mechanically sieved (Bertel Ind. Metal., Brazil) to furnish particles that ranged from 9 to 16 -mesh.

\section{Soxhlet Extraction}

For determining the total extractable triterpene acids, two samples of milled apple dry peels $(5 \mathrm{~g})$ were separately placed in Soxhlet cartridges $(100 \mathrm{~mL})$ and extracted with $250 \mathrm{~mL}$ methanol. Separately ethanol also was applied as extraction solvent. Three independent 2-h cycles were performed for each extractive path by conveniently re-feeding the system with equal amounts of the same solvent. Thereafter, the solvent was removed to produce three sequential batches of peel extracts for each tested solvent. All the procedures were performed in triplicate. The extraction yield in each cycle was determined gravimetrically by the ratio between masses of dried extract and peel. The contents of each triterpene acid were quantitatively assessed by HPLC in all the extracts. The recovery of each cycle was determined based of the total mass after the complete extraction, because less than onehundredth of mass was extracted in the third cycle, demonstrating that the apple peels exhaustion has been virtually complete.

\section{Alkaline Ethanol Extraction}

In a 1-liter Erlenmeyer flask, dried milled apple peels (25 g) were suspended in an ethanolic sodium hydroxide solution ( $5 \mathrm{~g} \mathrm{NaOH}$ in $250 \mathrm{~mL} 95 \%$ ethanol). The mixture was shaken on an IKA KS130 Basic (IkaWerke GmbH \& Co., GE) orbital shaker (550 rpm) for 6 
$\mathrm{h}$ at room temperature $\left(20-25^{\circ} \mathrm{C}\right)$. It was filtered by gravity using filter paper (grade 4 Whatman), and the filtrate was placed in a rotary evaporator to reduce the ethanol to one tenth of the initial volume. To this residue, $60 \mathrm{~mL}$ of $5 \% \mathrm{HCl}$ was added under stirring, and the resulting suspension $(\mathrm{pH} 3.0)$ was placed in the refrigerator for $1 \mathrm{~h}$. It was filtered through a Buchner funnel recovering a whitish solid that was washed with chilled distilled water, transferred to a weighted glass vial, and then submitted to high vacuum for $48 \mathrm{~h}$. The resultant solid was kept in an electronic desiccator cabinet (Dry-Keeper Auto C-3B, Sanplatec Corp., JP) until the analyses.

The same sequence of experiments was performed for the previously defatted dry peels of AF2. The defatting procedure consisted of soaking the material $(150 \mathrm{~g})$ in $n$-hexane $(2 \times 250$ $\mathrm{mL}$ ) for 4 days at room temperature, followed by filtration and removing the solvent. Except for the soaking in hexane, all experimental procedures were conducted in triplicate.

\section{Apparatus and HPLC Analysis}

The percentage weight contents of each triterpene acid in the extracts were based on HPLC analysis after building of independent calibration curves. A methanol solution of the mixture of both acids (10 $\mathrm{mg}$ each, $\pm 0.01 \mathrm{mg}$ precision) was prepared in a $25 \mathrm{~mL}$ volumetric flask and properly diluted in methanol to produce concentrations of $8,16,40,100,160$ and $200 \mu \mathrm{g} / \mathrm{mL}$. The HPLC injections $(20 \mu \mathrm{l})$ of these standard solutions were performed in triplicates to generate the calibration curves, as well as to evaluate the linearity and validity by analysis of variance (ANOVA). The signals at 20.5 and $21.5 \mathrm{~min}$ were assigned as oleanolic and ursolic acids, respectively. The regression equations for the calibration curves were $y=4073 x+2016(r=0.9996)$ for ursolic acid and $y=7293 x+4505(\mathrm{r}=0.9997)$ for

oleanolic acid, in which $y$ and $x$ represent, respectively, the integration area and the 
concentration $(\mu \mathrm{g} / \mathrm{mL})$ of the respective acid. Reproducibility was achieved with the percentage Relative Standard Deviation (\%RSD) less than 5\% for the integration areas at all concentrations.

The samples $(5.0 \mathrm{mg})$ that originated from the extraction with alkaline ethanol were dissolved in methanol $(10.0 \mathrm{~mL})$ via sonication (Model USC-1850, UNIQUE, Indaiatuba, $\mathrm{BR})$ at a frequency of $25 \mathrm{kHz}$ for $15 \mathrm{~min}$ at $25-30^{\circ} \mathrm{C}$. The dried extracts that originated from the Soxhlet extractions were diluted in methanol to adjust the chromatographic signals to the calibration range. All of the solutions were filtered through $0.20 \mu \mathrm{m}$ regenerated cellulose membranes (Sartorius, GE) prior to the injections.

The HPLC system, LC-10AVP (Shimadzu Co., Japan), consisted of two LC-10AD pumps, a DGU-12A degasser, a SIL-10AD autosampler, a CTO-10A column oven and a SPD-M10A photodiode array detector (PDA) programmed to scan at 200-350 $\mathrm{nm}$. The data analysis was performed using CLASS-VP v.6.13 SP2 software (Shimadzu). A SymmetryShield RP18 $(250 \times 4.6 \mathrm{~mm}, 5 \mu \mathrm{m}$, Waters, IR $)$ column connected to a Supelguard LC-18 guard column ( $2 \mathrm{~cm}$, Supelco, Bellefonte, PA, USA) was used for the analysis. The mobile phase consisted of $98: 2 \mathrm{v} / \mathrm{v}$ acetonitrile and $1.25 \% \mathrm{v} / \mathrm{v}$ phosphoric acid aqueous solution, in an isocratic elution for $35 \mathrm{~min}$ at a flow-rate of $0.6 \mathrm{~mL} / \mathrm{min}$ and at a temperature of $30{ }^{\circ} \mathrm{C}$. Twenty-microliter injections produced the chromatograms that were monitored by UV detection at $206 \mathrm{~nm}$. The chromatographic method to quantify the ursolic and oleanolic acids was based on Chen et al. [44] and adapted by Siani et al. [24].

\section{Statistical Analysis}

The means and Standard Deviation (SD) were determined from triplicate experiments of the extractive processes and calculated based on dried extract or peel. For each response 
parameter, the data were statistically evaluated using the one-way ANOVA, which was followed by Tukey's studentized range HSD test $(\mathrm{P}<0.01$ or $\mathrm{P}<0.05)$, to determine the significant differences between the pairs of results by applying the Action version 2.7 (Estatcamp, São Carlos, BR) software. For the construction of the linear calibration curves, the coefficient of determination (r), \%RSD and coefficients (slope and interception) were calculated by the least square method using Microsoft Office Excel 2007 software.

\section{RESULTS AND DISCUSSION}

Based on net weight of the apples, the dried peel yields ranged from $2.20 \%$ to $2.78 \%$ $(\mathrm{w} / \mathrm{w})$, regardless of the cultivar and the apple sizes. The manual peeling should be taken into account as a source of deviation in the results because the peel could be contaminated by apple pulp by up to $30 \%$ [45]. Fresh weights were not taken, but the literature reports a range from $5.1 \%$ to $7.1 \%$ for the peel of five distinct Chilean apple cultivars [46]. This value is admitted to fall grossly around $10 \% \mathrm{w} / \mathrm{w}$ [47]. The establishing of the exhaustion of peels was key to quantify the effectiveness of the further extraction with alkaline ethanol. Thus, the Soxhlet extraction was performed using three subsequent cycles to establish the maximum recovery of the triterpene acids from the apple peels (Table 1).

The use of methanol or ethanol as the Soxhlet solvent did not produce any significant differences in extract yields and triterpene acid recoveries for same cultivar (AF3/methanol versus AF3/ethanol in Table 1). Yields for the Fuji apple peels (AF3/ethanol) were 12\% (w/w) higher than for the Gala ones (AG1/ethanol) and similar chromatograms were obtained from ethanol extracts of both apple cultivars (Fig. $2 \mathrm{a}$ and $2 \mathrm{~b}$ ). This result may be attributed to the different fruit peel thicknesses that are due to the distinct apple varieties [48]. Additionally, the extractable cutine and other compounds may be unequal in both 
cultivars. Since that $2 \mathrm{~h}$ was enough to recover $96-97 \%$ of the total extract mass from both cv. Fuji and Gala, regardless of the used alcohol (first-cycles in Table 1), complete exhaustion of the triterpene acids from the peels by the three-cycle Soxhlet extraction can be considered. This finding is also important for any scaling-up the Soxhlet extraction.

Overall, the results obtained from the aforementioned studies in the literature on the apple peels inspired the effort to obtain their lipophilic and triterpene-rich extracts by devising an advantageous one-step protocol. The alkaline ethanol produced approximately 15 - and 11times less crude extracts than those produced by the Soxhlet method (NaOH/ethanol versus Soxhlet/ethanol in Table 2) for the Fuji (AF3) and Gala (AG1) apple peels, respectively. The overall yields by the alkaline ethanol procedure averaged between $4.3 \%$ and $6.9 \%(\mathrm{w} / \mathrm{w}$ dried peels) against 58.7- 67.3\% Soxhlet extraction yields ( $\mathrm{NaOH}$ versus Soxhlet in Table 2). For alkaline ethanol process $(\mathrm{NaOH}$ in Table 2$)$, the differences $(\mathrm{P}<0.01)$ within the batches from the same cultivars (AF or AG) may be due to fruit seasoning and eventual post-harvest treatments [49].

The two methods produced very different extracts with respect to both the physical aspects and the chemical constitution. All alkaline treatment of the dried apple peels in ethanol produced whitish, non-viscous, and highly hydrophobic solids. As expected, a more complex composition can be observed in the low-retention region between 5 and 15 min in the reversed-phase HPLC-DAD profile of the Soxhlet extracts in which the most polar phenolic and derivatives elute (Fig. 2a versus $2 \mathrm{c}$ for $\mathrm{AF} 3$, and $2 \mathrm{~b}$ versus $2 \mathrm{~d}$ for $\mathrm{AG} 1$ ). Filtration of the acidic solution and water washing, at the end of the alkaline ethanol process, likely eliminated the residual aromatic acid derivatives from the cutin hydrolysis, other hydrophilic flavonoids and sugars. The non-pigmented final products and the chromatograms (Fig. 2c and 2d) relatively devoid of significant signals below $15 \mathrm{~min}$ for several wavelengths corroborated partially the above assumption. 
The ursolic and oleanolic acid contents in the extracts of AF1 were much different $(\mathrm{P}<$ 0.01) to those found in the other Fuji batches (Table 2). The AF3 consistently $(\mathrm{P}<0.05)$ presented the lowest abundances of both acids in the peels and a much lower $(\mathrm{P}<0.01)$ crude extract amount, which indicates that distinct triterpene acid amounts may be found in apple peels from the same cultivars. The values for the Gala peel fell within the large range of dispersion displayed by the Fuji peels. Therefore, the effectiveness of the alkaline extraction could not be compared between these two cultivars. No significant difference $(\mathrm{P}>$ 0.05) for the ratio of ursolic to oleanolic acids was observed among the Fuji peel extracts when using the alkaline ethanol process, demonstrating that there is no selectivity in extraction for any triterpene acid. The ratio of ursolic to oleanolic acid in AG1 was much lower $(\mathrm{P}<0.01)$ than all of the other apple batches after alkaline extraction or Soxhlet extractions. In fact, extracts from the alkaline ethanol process showed ratio values between ursolic and oleanolic acids lower than those from the Soxhlet extraction $(\mathrm{P}<0.01$ for AF3 and $\mathrm{P}<0.05$ for $\mathrm{AG} 1$ ), indicating that the extraction of the oleanolic acid was slightly favored over ursolic acid in the former process. Taking together, the results suggest that there were no significant differences in the recovery of ursolic or oleanolic acids for the employed methods (comparing Soxhlet to $\mathrm{NaOH}$ for same batch in Table 2). Given that the Soxhlet extraction exhausted the triterpene acids, the alkaline extraction method showed to be as well effective for this purpose.

The content of both ursolic and oleanolic acids decreased by $4.8 \%$ and $4.5 \%$ (statistically not significant) in the defatted extract for the Fuji peels (comparing AF2 in Table 2). This variation was coincident with an increasing extract yield of $13 \%(\mathrm{w} / \mathrm{w})(\mathrm{P}<0.01)$, suggesting that the removal of the superficial waxes does imply a higher extractive capacity by using the alkaline protocol. The overall extractable ursolic and oleanolic acids from the 
peels was not different $(\mathrm{P}>0.05)$ for all of the alkaline extracts of the Fuji apple; thus, defatting did not appear to affect the acid recovery.

\section{CONCLUSIONS}

This study presented a method to obtain extracts from apple peels that are natural source abundantly available and rich in ursolic and oleanolic acids. The method includes treating the dried raw material with $2 \% \mathrm{NaOH}$ solution in hydrated ethanol. This procedure enhances the solubility of the triterpene acids, avoids extract contamination by the intractable polymeric cutin (which is hydrolyzed) and suppresses the usual first step of producing an organic extract. The relatively smooth experimental conditions employed led to a depletion of the triterpenes from the apple peel. These results were quantitatively corroborated by the statistical similarity to the Soxhlet extractions that used absolute alcohols as the solvents. The extraction utilizes low-energy conditions and an environmentally friendly process because it produces sodium chloride and water as the disposable residues. A highly selective process that favors the concentration of lipophilic acids in a relatively clean extract would also be advantageous for proceeding successfully for the isolation of triterpene acids, particularly ursolic acid, from apple peels. Taking in account its relative abundance in apple peels and the availability of this raw material in residues of the food and beverage industries, a large-scale process to isolate and purify such a triterpene compound could be devised via a cost-effective extraction step. 


\section{ACKNOWLEDGEMENTS}

We acknowledge the Brazil National Counsel for Technological and Scientific Development for the grant that partially supported this project (474751/2009-0) and for the fellowship (PIBIC/CNPq) to C.G.F. de Saboya. This study also was supported by RPTPDTIS/Fiocruz.

\section{REFERENCES}

1. Jetter, R.; Kunst, L.; Samuels, L. (2006) Composition of plant cuticular waxes. In: Riederer, M.; Müller C. (Eds.), Biology of the plant cuticle, Blackwell Publishing: Oxford, U.K., pp. 145-181.

2. Liu, J. (2005) Oleanolic acid and ursolic acid: Research perspectives. J. Ethnopharmacol., 100: 92-94.

3. Jäger, S.; Winkler, K.; Pfüller, U.; Scheffer, A. (2007) Solubility studies of oleanolic acid and betulinic acid in aqueous solutions and plant extracts of Viscum album L. Planta Med., 73: 157-162.

4. Jäger, S.; Laszczyk, M.N.; Strüh, C.M.; Martin, S.F.; Scheffler, A. (2008) Triterpenes from natural sources for parenteral and topical application. Planta Med., 74 (9): PC-137.

5. Jäger, S.; Trojan, H.; Kopp, T.; Laszczyk, M.N.; Scheffler, A. (2009) Pentacyclic triterpene distribution in various plants - rich sources for a new group of multi-potent plant extracts. Molecules, 14: 2016-2031.

6. Wolfe, K.; Liu, R.H. (2003) Apple peels as a value-added food ingredient. J. Agr. Food Chem., 51: 1676-1683. 
7. Cao, X.; Wang, C.; Pei, H.; Sun, B. (2009) Separation and identification of polyphenols in apple pomace by high-speed counter-current chromatography and high-performance liquid chromatography coupled with mass spectrometry. J. Chromatogr. A, 1216: 42684274.

8. Wolfe, K.; Wu, X.; Liu, R.H. (2003) Antioxidant activity of apple peels. J. Agr. Food Chem., 51: 609-614.

9. Peschel, W.; Sánchez-Rabaneda, F.; Diekmann, W.; Plescher, A.; Gartzía, I.; Jiménez, D.; Lamuela-Raventós, R.; Buxaderas, S.; Codina, C. (2006) An industrial approach in the search of natural antioxidants from vegetable and fruit wastes. Food Chem., 97: 137-150.

10. Sando, C.E. (1931) Ursolic acid. J. Biol. Chem., 90: 477-495.

11. Bringe, K.; Schumacher, C.F.; Schimitz-Eiberger, M.; Steiner, U.; Oerke, E.C. (2006) Ontogenetic variation in chemical and physical characteristics of adaxial apple leaf surfaces. Phytochemistry, 67 (2): 161-170.

12. Frighetto, R.T.S.; Welendorf, R.M.; Nigro, E.; Frighetto, N.; Siani, A.C. (2008) Isolation of ursolic acid from apple peels by high speed counter-current chromatography. Food Chem., 106: 767-771.

13. Jetter, R.; Schaffer, S. (2001) Chemical composition of the Prunus laurocerasus leaf surface. Dynamic changes of the epicuticular wax film during leaf development. Plant Physiol., 126: 1725-1737.

14. Verardo, G.; Pagani, E.; Geatti, P.; Martinuzzi, P. (2003) A thorough study of the surface wax of apple fruits. Anal. Bioanal. Chem., 376: 659-667.

15. McGhie, T.K.; Hudault, S.; Lunken, R.C.M.; Christeller, J.T. (2012) Apple peels, from seven cultivars, have lipase-inhibitory activity and contain numerous ursenoic acids as identified by LC-ESI-QTOF-HRMS. J. Agric. Food Chem., 60: 482-491. 
16. Kolattukudy, P.E. (1980) Biopolyester membranes of plants: cutin and suberin. Science, 208: 990-1000.

17. Sando, C.E. (1923) Constituents of the wax-like coating on the surface of the apple. $J$. Biol. Chem., 56: 457-468.

18. Chibnall, A.C.; Piper, S.H.; Pollard, A.; Smith, J.A.B.; Williams, E.F. (1931) CCXXVI. The wax constituents of the apple cuticle. Biochem. J., 25: 2095-2110.

19. Huelin, F.E. Gallop, R.A. (1951) Studies in the natural coating of apples. I. Preparation and properties of fractions. Aust. J. Biol. Sci., 4 (4): 526-533.

20. Lawrie, W.; McLean, J.; El-Garby Younes, M. (1967) Triterpenoids in apple peel. $J$. Chem. Soc. C, 851-854.

21. Glen, A.T.; Lawrie, W.; Mclean, J.; El-Garby Younes, M. (1967) Triterpenoid constituents of rose-bay willow-herb. J. Chem. Soc. C, 510-515.

22. Jin, I.J.; Ko, Y.I.; Kim, Y.M.; Han, S.K. (1997) Solubilization of oleanolic acid and ursolic acid by cosolvency. Arch. Pharm. Res., 20: 269-274.

23. Merck Research Laboratories (1989) The Merck Index, 11th Ed.; Merck and Co.: Rahway, U.S.A. pp. 1171, 1686.

24. Siani, A.C.; Nakamura, M.J.; Santos, D.S. dos; Mazzei, J.L.; Nascimento, A.C. do; Valente, L.M.M. (2014) Efficiency and selectivity of triterpene acid extraction from decoctions and tinctures prepared from apple peels. Pharmacog. Mag., 10: 225-231.

25. Wei, M.-C.; Yang, Y.-C. (2014) Extraction characteristics and kinetic studies of oleanolic and ursolic acids from Hedyotis diffusa under ultrasound-assisted extraction conditions. Sep. Purif. Technol., 130: 182-192.

26. Martelanc, M.; Vovk, I.; Simonovska, B. (2009) Separation and identification of some common isomeric plant triterpenoids by thin-layer chromatography and high-performance liquid chromatography. J. Chromatog. A, 1216: 6662-6670. 
27. Yamaguchi, H.; Noshita, T.; Kidashi, Y.; Umetsu, H.; Hayashi, M.; Komiyama, K.; Funayama, S.; Ryoyama, K. (2008) Isolation of ursolic acid from apple peels and its specific efficacy as a potent antitumor agent. J. Health Sci., 54 (6): 654-660.

28. D’Abrosca, B.; Pacifico, S.; Cefarelli, G.; Mastellone, C.; Fiorentino, A. (2007) 'Limoncella' apple, an Italian apple cultivar: Phenolic and flavonoid contents and antioxidant activity. Food Chem., 104: 1333-1337.

29. Huelin, F.E. (1959) Studies in the natural coating of apples. IV. The nature of cutin. Aust. J. Biol. Sci., 12: 175-180.

30. Massini, L.; Rico, D.; Diana, A.B.M.; Barry-Ryan, C. (2013) Valorisation of Apple Peels. European J. Food Res. \& Rev., 3 (1): 1-15.

31. Lu, Y.; Foo, L.Y. (2000) Antioxidant and radical scavenging activities of polyphenols from apple pomace. Food Chem., 68: 81-85.

32. Goulas, V.; Manganaris, G.A. (2012) Towards an efficient protocol for the determination of triterpenic acids in olive fruit: A comparative study of drying and extraction methods. Phytochem. Anal., 23: 444-449.

33. Baker, E.A.; Deas, A.H.B. (1973) Epoxydecanoic acids in plant cutins and suberins. Phytochemistry, 12: 1721-1735.

34. Eglinton, G.; Hunneman, D.H. (1968) Gas chromatographic-mass spectrometry studies of long-chain hydroxyl acids - I. The constituent cutin acids of apple cuticle. Phytochemistry, 7: 313-322.

35. Baker, E.A.; Holloway, P.J. (1970) The constituent acids of Angiosperm cutins. Phytochemistry, 9: 1557-1562.

36. Davenport, J. (1956) Studies in the natural coating of apples. III. Saturated acids of the cuticle oil, Aust. J. Chem., 9: 416-419. 
37. Pereira, S.I.; Freire, C.S.; Neto, C.P.; Silvestre, A.J.; Silva, A.M. (2005) Chemical composition of the epicuticular wax from the fruits of Eucalyptus globulus. Phytochem. Anal., 6: 364-369.

38. Domingues, R.; Sousa, G.; Silva, C.; Freire, C.S.R.; Silvestre, A.J.D.; Pascoal Neto, C. (2011) High value triterpenic compounds from the outer barks of several Eucalyptus species cultivated in Brazil and in Portugal. Ind. Crop. Prod., 33: 158-164.

39. Holloway, P.J.; Deas, A.H.B. (1973) Epoxyoctadecanoic acids in plant cutins and suberins. Phytochemistry, 12: 1721-1735.

40. Craig, B. D.; Anderson, D. B. (Eds.). (2002) Handbook of corrosion data, ASM International: Materials Park, U. S. A., pp. 761-790.

41. Ellgardt, K. (2006) Triterpenes in apple cuticle of organically and IP cultivated apples. Bachelor Project in the Danish-Swedish Horticulture Programme; Swedish University of Agricultural Sciences: Alnarp, Sweden.

42. Lima, A.M.; d'Avila, L.A.; Siani, A.C. (2014) Comparison between methyl and trimethylsilyl ester derivatives in the separation and GC quantification of triterpene acids in Eugenia brasiliensis leaf extract. Chromatographia, 77 (7-8): 629-635.

43. Lima, A.M.; Siani, A.C.; Nakamura, M.J.; d'Avila, L.A. (2015) Selective and costeffective protocol to separate bioactive triterpene acids from plant matrices using alkalinized ethanol: Application to leaves of Myrtaceae species. Pharmacogn. Mag., 11 (43): $470-476$.

44. Chen, J.H.; Xia, Z.H.; Tan, R.X. (2003) High-performance liquid chromatographic analysis of bioactive triterpenes in Perilla frutescens. J. Pharm. Biomed. Anal., 32: 11751179 
45. Łata, B.; Przeradzka, M.; Bińkowska, M. (2005) Great differences in antioxidant properties exist between 56 apple cultivars and vegetation seasons. J. Agric. Food Chem., 53: $8970-8978$.

46. Henríquez, C.; Speisky, H.; Chiffelle, I.; Valenzuela, T.; Araya, M.; Simpson, R.; Almonacid, S. (2010) Development of an ingredient containing apple peel, as a source of polyphenols and dietary fiber. J. Food Sci., 75 (6): H172-H181.

47. Huber, G.M.; Rupasinghe, H.P.V. (2009) Phenolic profiles and antioxidant properties of apple skin extracts, J. Food Sci., 74: C693-C700.

48. Homutová, I.; Blažek J. (2006) Differences in fruit skin thickness between selected apple (Malus domestica Borkh.) cultivars assessed by histological and sensory methods. Hort. Sci. (Prague), 33 (3): 108-113.

49. Markley, K.S.; Sando, C.E. (1933) Progressive changes in the cuticle of apples during growth and storage. J. Agric. Res., 46 (5): 403-412. 
FIG. 1

Chemical structure of ursolic acid<smiles>C[C@H]1CC[C@]2(C(=O)O)CC[C@H]3C(=CC[C@@H]4[C@@]5(C)CC[C@@H](O)C(C)(C)C5CC[C@]43C)[C@]2(C)[C@@H]1C</smiles> 
FIG. 2

Typical HPLC chromatograms of the dried peel extracts by Soxhlet extraction using ethanol for AF3 (a) and AG1 (b) and by alkalinized ethanol extraction for AF3 (c) and AG1 (d). The Soxhlet methanol extract for AF3 afforded a quite similar profile to (a). OA = oleanolic acid; $\mathrm{UA}=$ ursolic acid
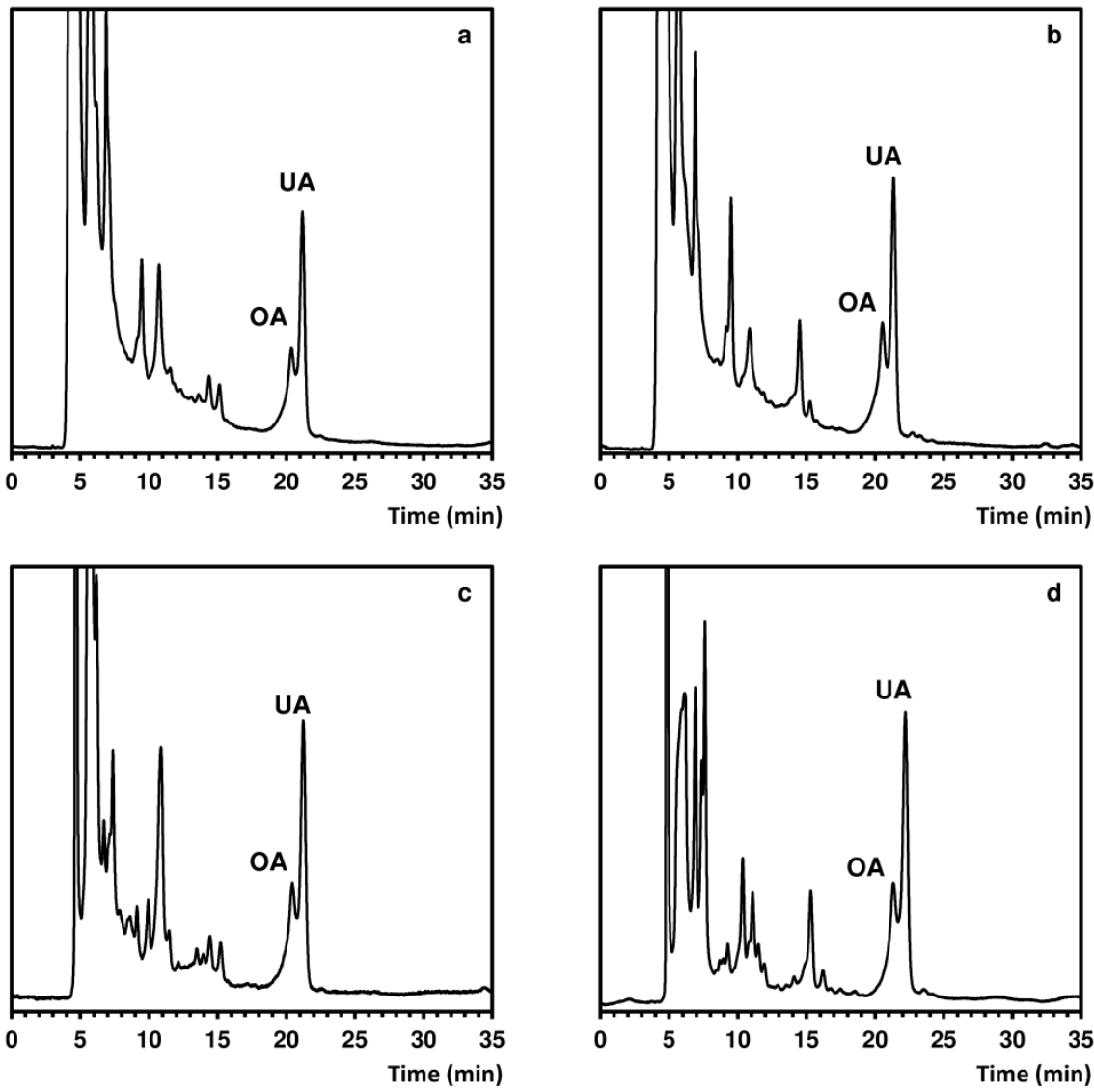
TABLE 1 Extract yields and contents of ursolic (UA) and oleanolic (OA) acids from Fuji (AF3) and Gala (AG1) peels after Soxhlet extractions

\begin{tabular}{|c|c|c|c|c|c|}
\hline $\begin{array}{l}\text { Batch/solv } \\
\text { ent }\end{array}$ & $\begin{array}{c}\text { Cy } \\
\text { cle }^{a}\end{array}$ & $\begin{array}{l}\text { Extract } \\
\text { yield }^{b}\end{array}$ & $\begin{array}{l}\text { Recov } \\
\text { ery }^{c}\end{array}$ & $\begin{array}{r}\% \\
\mathrm{UA}^{d}\end{array}$ & $\begin{array}{r}\% \\
\mathrm{OA}^{d}\end{array}$ \\
\hline $\begin{array}{l}\text { AF3/Metha } \\
\text { nol }\end{array}$ & $1 \mathrm{st}$ & $64.15 \%$ & $97.1 \%$ & $\begin{array}{l}1.4 \\
5\end{array}$ & $\begin{array}{l}0.1 \\
7\end{array}$ \\
\hline $\begin{array}{l}\text { AF3/Metha } \\
\text { nol }\end{array}$ & $\begin{array}{l}2 n \\
d\end{array}$ & $1.68 \%$ & $2.54 \%$ & $\begin{array}{l}1.1 \\
1\end{array}$ & $\begin{array}{l}0.1 \\
2\end{array}$ \\
\hline $\begin{array}{l}\text { AF3/Metha } \\
\text { nol }\end{array}$ & 3 th & $0.21 \%$ & $0.32 \%$ & $\begin{array}{l}0.2 \\
0\end{array}$ & 2 \\
\hline $\begin{array}{l}\text { AF3/Ethan } \\
\text { ol }\end{array}$ & $1 \mathrm{st}$ & $65.2 \%$ & & & $\begin{array}{l}0.1 \\
7\end{array}$ \\
\hline $\begin{array}{l}\text { AF3/Ethan } \\
\text { ol }\end{array}$ & $\begin{array}{l}2 n \\
d\end{array}$ & & & $\begin{array}{l}0.9 \\
4\end{array}$ & $\begin{array}{l}0.1 \\
0\end{array}$ \\
\hline $\begin{array}{l}\text { AF3/Ethan } \\
\text { ol }\end{array}$ & 3 th & & $0.67 \%$ & $\begin{array}{l}0.1 \\
5\end{array}$ & n.d \\
\hline $\begin{array}{l}\text { AG1/Ethan } \\
\text { ol }\end{array}$ & & $56.3 \%$ & $95.9 \%$ & $\begin{array}{l}1.9 \\
5\end{array}$ & $\begin{array}{l}0.2 \\
5\end{array}$ \\
\hline AG1/Etha & $\begin{array}{l}2 \mathrm{n} \\
\mathrm{d}\end{array}$ & $2.44 \%$ & $4.16 \%$ & $\begin{array}{l}0.6 \\
3\end{array}$ & $\begin{array}{l}0.0 \\
9\end{array}$ \\
\hline $\begin{array}{c}\text { AG1/Ethan } \\
\text { ol }\end{array}$ & 3th & n.d. & n.d. & n.d & n.d \\
\hline
\end{tabular}

${ }^{a}$ Cycles were defined by solvent-feeding at each 2 hours; values are mean of three replications. ${ }^{b}$ Averaged from extractions in triplicate, calculated $(\mathrm{w} / \mathrm{w})$ on the dried peel mass basis. ${ }^{c}$ Relative to the sum of recovering from the three-cycle process. ${ }^{d}$ Contents of ursolic and oleanolic acids in crude extract (w/w) were assessed by HPLC; values are mean of analysis in triplicates. n.d. $=$ not detected. 
TABLE 2 Yields and characterization of the apple peel extracts obtained by Soxhlet and alkalinized ethanol methods

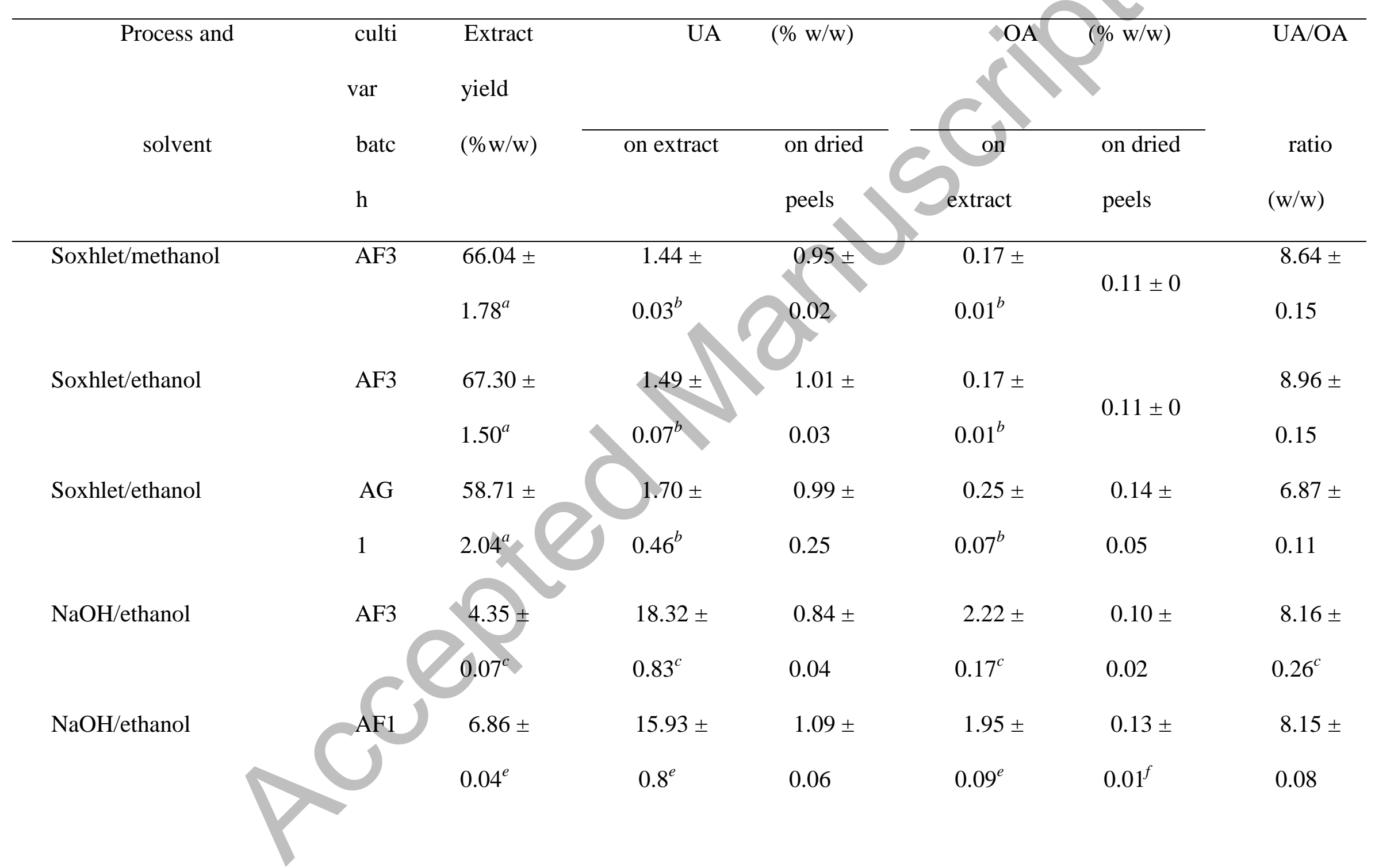




\begin{tabular}{|c|c|c|c|c|c|c|c|c|}
\hline \multirow[t]{2}{*}{$\mathrm{NaOH} /$ ethanol } & & $\mathrm{AF} 2$ & $5.01 \pm$ & $21.99 \pm$ & $1.11 \pm$ & $2.68 \pm$ & $0.14 \pm$ & $8.22 \pm$ \\
\hline & & & $0.08^{e, g}$ & 0.83 & $0.06^{f}$ & 0.05 & $0.00^{f}$ & 0.16 \\
\hline $\mathrm{NaOH} /$ ethanol & after & $\mathrm{AF} 2$ & $5.77 \pm$ & $20.94 \pm$ & $1.20 \pm$ & & $0.15 \pm$ & $8.18 \pm$ \\
\hline defatting & & & $0.15^{h}$ & 0.49 & 0.06 & 0.03 & 0.01 & 0.10 \\
\hline \multirow[t]{2}{*}{$\mathrm{NaOH} /$ ethanol } & & $\mathrm{AG}$ & $5.14 \pm$ & $20.63 \pm$ & 1.06 & $3.19 \pm$ & $0.16 \pm$ & $6.46 \pm$ \\
\hline & & 1 & $0.15^{c}$ & $1.71^{c}$ & & $0.25^{c}$ & 0.01 & $0.04^{d}$ \\
\hline \multirow[t]{2}{*}{$\mathrm{NaOH} /$ ethanol } & & $\mathrm{AG}$ & $5.33 \pm$ & 23.62 & 26 & $2.96 \pm$ & $0.16 \pm$ & $7.98 \pm$ \\
\hline & & 2 & 0.20 & 2.59 & 0.10 & 0.27 & 0.01 & $0.17^{e}$ \\
\hline
\end{tabular}

